\title{
A cross-Canada survey of cytomegalovirus prevention and treatment practices in bone marrow transplant recipients
}

\author{
Atul Humar MD FRCPC ${ }^{1,3}$, Jeff Lipton MD FRCPC ${ }^{2,3}$, Hans Messner MD FRCPC ${ }^{2,5}$, Allison McGeer MD FRCPC , $^{6}$
} Tony Mazzulli MD FRCPC ${ }^{7}$

\begin{abstract}
A Humar, J Lipton, H Messner, A McGeer, T Mazzulli. A cross-Canada survey of cytomegalovirus prevention and treatment practices in bone marrow transplant recipients. Can J Infect Dis 1999;10(6):410-415.

OBJECTIVE: To gather information about cytomegalovirus (CMV) prevention and treatment practices in bone marrow transplantation (BMT) in Canada.

DESIGN: A questionnaire was mailed to all centres across Canada performing BMT in January 1998. A second mailing was sent three months later.

POPULATION STUDIED: Data on 15 centres performing allogeneic BMT (total patients 459) and 16 centres (total patients 703) performing autologous BMT were obtained.

RESULTS: For allogeneic BMT, all donors and recipients had pretransplant CMV serology performed. Nine centres gave CMV-negative blood to only donor-negative/recipient-negative patients, four centres to all patients and two centres to other subgroups. All allogeneic BMT centres had a strategy for CMV prevention. Three centres used universal ganciclovir prophylaxis, while 12 centres used some form of pre-emptive ganciclovir therapy based on weekly antigenemia assays (four centres), weekly polymerase chain reaction (two centres), CMV blood cultures (one centre), CMV throat and urine cultures (one centre), CMV screening bronchoscopy (two centres), or a combination of antigenemia plus bronchoscopy (two centres). The dose and duration of pre-emptive ganciclovir varied considerably from centre to centre. In addition, many centres used high dose acyclovir universally for a variable period of time post-BMT. For the treatment of CMV pneumonia, 14 centres used ganciclovir plus immunoglobulin (IG) and one centre used ganciclovir alone. Ganciclovir treatment duration ranged from two to 11 weeks and the number of doses of IG from three to 18. Thirteen of 16 autologous BMT centres screened patients for CMV pretransplant. Ten centres used CMV negative blood for some or all of their patients. Only one centre performed routine CMV monitoring after autologous BMT.

CONCLUSIONS: Practices for the prevention of CMV disease in BMT patients differ widely across centres, and further data may assist in developing a consensus regarding the optimal approach to CMV management.
\end{abstract}

Key Words: Bone marrow transplantation; Cytomegalovirus

voir page suivante

\footnotetext{
${ }^{1}$ Department of Medicine, Division of Infectious Diseases, The Toronto Hospital; ${ }^{2}$ Department of Medical Oncology and Hematology, ${ }^{3}$ University of Toronto; ${ }^{4}$ Allogenic Bone Marrow Transplant Program, Princess Margaret Hospital; ${ }^{5}$ Allogenic Bone Marrow Transplant Program, University Network, University of Toronto; Department of Pathobiology and Laboratory Medicince, Medicine and Public Health Sciences, University of Toronto; Department of Laboratory Medicine and Pathobiology, University of Toronto; Department of Microbiology, Mount Sinai and Princess Margaret Hospital, Toronto, Ontario

Correspondence and reprints: Dr Tony Mazzulli, Department of Microbiology, Mount Sinai Hospital, 600 University Avenue, Toronto, Ontario M5G 1X5. Telephone 416-586-4695, fax 416-586-8746, e-mail tmazzulli@mtsinai.on.ca

Received for publication October 28, 1998. Accepted February 2, 1999
} 


\title{
Enquête pancanadienne sur la prévention du cytomégalovirus et sur les pratiques de traitement chez les receveurs d'une greffe de moelle osseuse
}

\begin{abstract}
OBJECTIF : Recueillir de l'information sur la prévention du cytomégalovirus (CMV) et sur les pratiques de traitement chez les receveurs d'une greffe de moelle osseuse au Canada.

MODÈLE : Un questionnaire a été posté à tous les centres pratiquant des greffes de moelle osseuse au Canada en janvier 1998. Un nouveau questionnaire a été posté trois mois après.

POPULATION ÉTUDIÉE : Les données de 15 centres pratiquant des greffes de moelle osseuse allogéniques (459 patients au total) et de 16 centres (703 patients au total) pratiquant des greffes de moelle osseuse autologues ont été recueillies.

RÉSULTATS : Dans les cas des greffes de moelle osseuse allogéniques, l'ensemble des donneurs et des receveurs avaient subi une sérologie de dépistage du CMV avant la transplantation. Neuf centres donnaient du sang négatif pour le CMV seulement aux patients donneurs et receveurs dont la sérologie était négative pour le CMV, quatre centres à tous les patients et deux centres à d'autres sous-groupes. Tous les centres pratiquant des greffes de moelle osseuse allogéniques adoptaient une stratégie de prévention contre le CMV. Trois centres utilisaient une prophylaxie universelle avec du ganciclovir, alors que 12 centres utilisaient une certaine forme de traitement préemptif au ganciclovir basé sur des dosages hebdomadaires de l'antigénémie cytomégalique (quatre centres), l'amplification en chaîne par polymérase (deux centres), des hémocultures pour la recherche du CMV (un centre), des cultures de gorge et/ou d'urine (un centre), des bronchoscopie de dépistage du $\mathrm{CMV}$ (deux centres) ou une combinaison de dosages de l'antigénémie cytomégalique et de bronchoscopies (deux centres). La dose et la durée du traitement préemptif au ganciclovir variaient considérablement d'un centre à un autre. De plus, de nombreux centres utilisaient de façon universelle une forte dose d'acyclovir pendant une période de temps variable après la transplantation de moelle osseuse. Pour le traitement de la pneumonie à CMV, 14 centres utilisaient du ganciclovir associé à des immunoglobulines (IG) et un centre utilisait seulement du ganciclovir. La durée du traitement au ganciclovir allait de deux à 11 semaines et le nombre de doses d'IG de trois à 18. Treize des 16 centres pratiquant des greffes de moelle autologues pratiquaient des tests de dépistage du CMV chez les patients avant la transplantation. Dix centres utilisaient du sang négatif pour le CMV pour certains ou pour l'ensemble de leurs patients. Seul un centre pratiquait une surveillance systématique du CMV après une greffe de moelle osseuse autologue.

CONCLUSIONS : Les pratiques de prévention de la maladie à CMV chez les patients recevant une greffe de moelle osseuse varient grandement d'un centre à un autre. Des données supplémentaires pourraient permettre de développer un consensus sur l'approche optimale de la prise en charge du CMV.
\end{abstract}

$\mathrm{I}^{\mathrm{r}}$ nfections caused by cytomegalovirus (CMV) remain a major cause of morbidity in patients undergoing allogeneic bone marrow (BMT) or peripheral blood stem cell (PBSC) transplantation $(1,2)$. The most common manifestations of active CMV disease in these patients include CMV pneumonitis and gastrointestinal (GI) disease, the former being associated with a high mortality rate despite aggressive treatment with ganciclovir and immunoglobulin $(3,4)$. CMV seropositive recipients of autologous grafts have been recognized to be at risk for developing serious CMV disease, although at a lower rate than allogeneic transplant recipients $(5,6)$.

Significant advances in the management of CMV infection and disease have been made in recent years. These have included the development of more sensitive and rapid diagnostic tests for the detection of CMV, and improved regimens for the treatment and prevention of active CMV disease, both of which have been incorporated into a variety of prophylactic and preemptive strategies $(7,8)$. Universal prophylaxis involves the administration of antiviral therapy to all BMT recipients at risk of developing CMV disease. Pre-emptive strategies involve monitoring patients for evidence of CMV reactivation followed by the subsequent administration of 'pre-emptive' therapy before the development of symptoms (7-10).

Given the rapidly evolving nature of this field, it is important to determine current clinical practices to help guide further research to gather data that will help optimize clinical care. To evaluate the current practices in Canada regarding the approach to CMV infection and disease after allogeneic and autologous BMT, we performed a Canada-wide survey of all institutions performing BMT, with questions focusing on CMV screening, prevention and treatment.

\section{MATERIALS AND METHODS}

A questionnaire was mailed to all autologous and allogeneic BMT transplant centres across Canada (date of first mailing January 1998) to obtain a snapshot of current practice patterns. A listing of centres was obtained from the Canadian Marrow Transplantation Registry in Ottawa, Ontario. Questionnaires were addressed to the head of the BMT program at each of the centres. The survey consisted of a two-page questionnaire requiring respondents to check the appropriate box or fill out short answers. Questions regarding CMV screening, prophylaxis, pre-emptive strategies, laboratory methodology and therapeutic regimens for patients undergoing allogeneic and autologous bone marrow or PBSC transplantation were included. A second mailing, approximately three months after the first, was used to elicit responses from those who did not reply initially. All statistical analysis was performed using SPSS version 7.5 (SPSS Inc, Chicago, Illinois).

\section{RESULTS}

Of the 20 centres listed in the Canadian Registry, all but two replied. Two centres performed only allogeneic transplants, three performed only autologous transplants and 13 performed both. According to the registry, the two centres that did not reply performed a total of 54 allogeneic transplants and 34 autologous transplants per year.

Allogeneic transplantation: Data on 15 centres performing allogeneic transplants were obtained. These centres perform a total of 347 bone marrow transplants and 111 PBSC transplants/year (total 458 transplants/year). On average, 349 procedures are related donor transplants and 109 are unrelated donor transplants. 
TABLE 1

Cytomegalovirus (CMV) prevention strategies for allogeneic transplants at 15 centres across Canada

\begin{tabular}{|c|c|c|}
\hline Centre & $\begin{array}{l}\text { Number of } \\
\text { transplants/year }\end{array}$ & $\mathrm{CMV}$ prevention strategy \\
\hline 1 & 45 & $\begin{array}{l}\text { Universal ganciclovir day }-7 \text { to } 0 \text {, and when absolute neutrophil count less than } 1.0 \text { to discharge. Also, weekly anti- } \\
\text { genemia day }-7 \text { to } 100 \text { with pre-emptive ganciclovir of variable duration }\end{array}$ \\
\hline 2 & 20 & $\begin{array}{l}\text { Weekly antigenemia day } 7 \text { until discharge; day } 35 \text { CMV surveillance bronchoscopy; pre-emptive ganciclovir for } \\
\text { four weeks }\end{array}$ \\
\hline 3 & 10 & Urine or throat cultures week one to four; pre-emptive strategy not stated \\
\hline 4 & 36 & $\begin{array}{l}\text { Ganciclovir three times/week for high risk subgroup based on pretransplant serology and whether donor mismatched } \\
\text { or unrelated }\end{array}$ \\
\hline 5 & 36 & $\begin{array}{l}\text { Ganciclovir three times/week for high risk subgroup based on pretransplant serology and whether donor mismatched } \\
\text { or unrelated }\end{array}$ \\
\hline 6 & 70 & Weekly antigenemia day 7 to 100 ; pre-emptive ganciclovir for four weeks \\
\hline 7 & 20 & Day 35 and 49 CMV surveillance bronchoscopy; pre-emptive ganciclovir until day 100 \\
\hline 8 & 20 & Weekly antigenemia day 28 to 100; day 35 and 49 bronchoavelolar lavage; pre-emptive ganciclovir for 10 weeks \\
\hline 9 & 29 & Weekly blood culture starting day 21 ; pre-emptive ganciclovir; polymerase chain reaction (PCR) under evaluation \\
\hline 10 & 35 & Weekly PCR day 14 to three to three to six months; pre-emptive ganciclovir of variable duration \\
\hline 11 & 10 & Weekly PCR day 21 to 100; pre-emptive ganciclovir \\
\hline 12 & 5 & Weekly antigenemia day 28-100; pre-emptive ganciclovir and immunoglobulin for 14 days \\
\hline 13 & 13 & Universal prophylaxis with ganciclovir: engraftment to day 100 \\
\hline 14 & 100 & Day $35 \mathrm{CMV}$ surveillance bronchoscopy; pre-emptive ganciclovir for 10 to 12 weeks \\
\hline 15 & 14 & Weekly antigenemia day -8 to 100 ; pre-emptive ganciclovir; duration based on repeat antigenemia \\
\hline
\end{tabular}

ANC Absolute neutrophil count

CMV screening and blood products management: All donors and recipients had pretransplant CMV serology performed. The rates of CMV-positive recipients ranged from $15 \%$ to $70 \%$ (median 50\%) and CMV-positive donors from $20 \%$ to $70 \%$ (median $50 \%$ ). The type of serological assay used for screening patients, donors and blood products was not collected in the survey. For transfusion requirements, all centres screened blood products for CMV. Nine centres reserved CMV-negative blood products only for donor-negative/recipient-negative patients; four centres used CMV-negative blood products in all patients, while two centres reported using CMV-negative products only if the donor or recipient were CMV seropositive. Three centres routinely used leukocyte filters in all patients, while two centres used them only when CMV-negative blood was unavailable for donor-negative/recipient-negative transplant patients.

CMV prevention strategies: All centres performing allogeneic transplantation had some form of CMV prevention strategy (Table 1). Prevention strategies differed considerably from centre to centre, with only two centres sharing the same protocol. Three centres used some form of universal ganciclovir prophylaxis (two of these centres used prophylaxis all patients in certain high risk subgroups) while the remaining 12 centres used various forms of pre-emptive therapy. No two pre-emptive strategies were the same. The virological techniques used to guide pre-emptive therapy included weekly antigenemia assay alone (four centres), weekly CMV polmerase chain reaction (PCR) (two centres), CMV blood cultures (one centre), CMV throat/urine cultures (one centre), screening bronchoscopy (two centres), or a combination of antigenemia plus a screening bronchoscopy (two centres). Pre-emptive screening started from eight days pretransplant to 35 days after transplant. Screening ended from four weeks to six months after transplant. At all centres, ganciclovir (Cytovene, Hoffmann-La Roche Limited, Mississauga, Ontario) was the drug employed for pre-emptive therapy. However, the dose, timing and duration of therapy varied across all centres. In addition, four of the centres using a pre-emptive strategy also gave universal high dose acyclovir for CMV prophylaxis. Again, the timing, dose, duration and route of administration differed among all of these centres.

Treatment of CMV disease: Ganciclovir was uniformly reported as the drug of choice for initial treatment of CMV disease. Induction doses of either $2.5 \mathrm{mg} / \mathrm{kg}$ every $8 \mathrm{~h}$ (three centres) or $5 \mathrm{mg} / \mathrm{kg}$ every $12 \mathrm{~h}$ (12 centres) were reported. Total duration of ganciclovir therapy (induction plus maintenance) varied from two weeks to longer than 10 weeks. Of 14 centres using adjunctive immunoglobulin as therapy for pneumonitis, 10 centres used regular intravenous immunoglobulin (IVIG) (majority used $0.5 \mathrm{~g} / \mathrm{kg} /$ dose), three used CMV hyperimmune globulin (CMVIG) (doses ranged from 200 to $400 \mathrm{mg} / \mathrm{kg} / \mathrm{dose}$ ), and one centre reported using either preparation. One centre reported using ganciclovir alone for treatment of CMV pneumonitis. The dosing schedule of IVIG or CMVIG varied considerably, with the total number of doses ranging from three to 18 spread over one to 11 weeks. For treatment of GI disease, centres reported using ganciclovir at the same dosing schedule as for pneumonitis, with only two centres using adjunctive immunoglobulin therapy.

Autologous transplantation: Data were gathered from 16 centres performing autologous transplantation. This included a total of 159 bone marrow transplants and 544 PBSC transplants/year (total 703 transplants/year). The mean number of transplants at each centre was 34.6.

CMV screening and blood products: Pretransplant CMV serology was performed at 13 of 16 autologous transplantation centres with $5 \%$ to $70 \%$ of patients reported as CMV positive (median 50\%). CMV-negative blood products were used at 10 of 16 centres and were given to all patients (two centres), only 
CMV-negative patients (seven centres) or only CMV-positive patients (one centre). Leukocyte filters were used by six of 16 centres for all patients (two centres), CMV-negative patients when negative blood products were not available (two centres), CMV-positive patients (one centre) and not stated (one centre).

CMV prevention and treatment: Only one centre performed routine CMV monitoring postautologous BMT. Treatment protocols for CMV pneumonitis and GI disease were generally similar to allogeneic protocols, with many centres not having a specific protocol for autologous transplant patients.

\section{DISCUSSION}

There is a great deal of literature on the prevention and treatment of CMV infection and disease especially in allogeneic BMT patients. This includes new therapeutic and preventative strategies as well as evaluations of recent advances in rapid and early detection of CMV using tests such as the CMV antigenemia assay or polymerase chain reaction $(7,8)$. Many of these published studies are uncontrolled and/or assess relatively small numbers of patients. The impact of these recent advances upon current clinical practice is unknown. The present study is the first to assess current practices with regards to CMV prevention and treatment at Canadian transplant centres. We demonstrate considerable variability in the approach to CMV among the different transplant centres.

Pretransplant CMV donor and recipient serology were performed at all allogeneic transplant centres. Such screening is extremely helpful in identifying those most at risk of CMV. The highest risk for CMV disease occurs in the CMV-seropositive recipient (11). The donor-negative/recipient-negative subgroup of patients has a very low rate of CMV disease if given CMV-negative blood products (12). The majority of centres reported using CMV-negative blood products in this group of patients or in all patients. The use of CMV-negative blood products has been shown to be effective only in the donornegative/ recipient-negative subgroup of patients $(12,13)$. CMV disease occurs at a much lower rate in autograft recipients. However, in one study, five of 88 (5.7\%) seronegative autograft recipients receiving unscreened blood products developed CMV pneumonitis (14). Therefore, it would seem prudent that CMV-negative recipients of autografts should receive CMV-negative blood products (15). Six autologous and six allogeneic centres also used leukocyte filters either routinely or when CMV-negative blood products were unavailable. Because the leukocyte fraction is assumed to be the site of latent $\mathrm{CMV}$, the use of filters in donor-negative/recipient-negative allogeneic transplants and recipient-negative autologous transplants is also likely to reduce the risk of CMV disease (16).

There are two clinical strategies that may be employed for the prevention of CMV disease postallogeneic BMT: universal prophylactic therapy and selective pre-emptive therapy $(7,8)$. Three centres reported using universal prophylaxis. Although this usually involves the administration of intravenous ganciclovir to all patients who are seropositive or who receive marrow from a seropositive donor, two centres restricted therapy further to mismatched or unrelated donors. Universal ganci- clovir prophylaxis has been shown to decrease the incidence of CMV infection and active CMV disease compared with placebo, but differences in overall mortality have not been consistently demonstrated $(17,18)$. This may be due to an increase in neutropenia and bacterial infections secondary to the toxicity of ganciclovir. Universal ganciclovir prophylaxis administration to all patients at risk of CMV disease is relatively costly, results in the administration of a potentially toxic medication to a large number of patients and may increase the risk for antiviral resistance.

The majority of centres reported using some form of preemptive therapy in which patients received ganciclovir based on laboratory evidence of CMV reactivation before the development of symptoms or end organ disease. This strategy has the advantage of selecting patients who are at highest risk of developing CMV disease and targeting them to receive antiviral therapy. Which strategy for CMV prevention is the most effective in preventing CMV disease is not known. Given the use of different diagnostic tests, disease definitions and the retrospective nature of such information, we did not collect data on CMV disease rates at each centre. We did not feel that a comparison of disease rates at the different institutions would provide an accurate assessment of the relative efficacy of different strategies. This information is best determined by welldesigned, controlled clinical trials.

To date, published studies evaluating various pre-emptive strategies have differed in the monitoring test(s) used to identify patients at highest risk and in the therapy instituted preemptively (dose, duration, etc). Schmidt et al (19) demonstrated that a pre-emptive strategy based on a day 35 postBMT surveillance bronchoscopy reduced mortality and CMV pneumonitis. Similarly, Goodrich et al (20) demonstrated a reduction in the incidence of active CMV disease when ganciclovir was administered to patients who excreted virus in blood, urine, throat washings or bronchoavelolar lavage fluid. In a trial comparing antigenemia guided pre-emptive therapy versus universal prophylaxis, the latter strategy was associated with a lower rate of CMV disease but an increase in invasive fungal infections (9). Randomized controlled trials comparing different pre-emptive strategies are limited (10), and the optimal strategy is unknown. Therefore, it is not surprising that a consensus does not exist.

Combination treatment with ganciclovir and immunoglobulin was the most commonly employed therapy for CMV pneumonitis. The evidence suggesting a benefit to use of immunoglobulin as an adjunct to ganciclovir is not based on randomized controlled trials, but rather on studies comparing outcomes to historical controls $(3,4)$. Therefore, improvements in mortality may in part be due to advances in early recognition and diagnosis. Despite the nature of the current evidence, the use of this combination seems logical in the face of extremely poor outcomes. Across Canada, dosing schedule and duration of ganciclovir plus immunoglobulin therapy varied widely from centre to centre. No evidence exists to support the use of adjunctive immunoglobulin for the therapy of GI disease (21). This in keeping with current clinical practice in most Canadian centres. 
The probability of developing CMV disease is significantly lower in autologous versus allogeneic BMT patients but may still occur in $4 \%$ to $9 \%$ of CMV-seropositive autologous transplant patients $(5,6)$. Risk factors and predictors for CMV disease have not been well defined in this population. Boeckh et al (6) demonstrated that $38.8 \%$ of seropositive autologous BMT or PBSC recipients had a positive CMV antigenemia after transplant, but only two of these patients developed CMV pneumonitis. An evaluation of CMV PCR after autologous transplantation demonstrated a 100\% negative predictive value but only a $2.5 \%$ positive predictive value for the development of CMV disease (22). There have been no reports of effective preventative strategies for CMV disease in seropositive autograft recipients, and routine monitoring for CMV is of uncertain benefit in this group. Many centres noted that CMV disease in autograft recipients was rare or that it had not been seen at their institution.

\section{REFERENCES}

1. Sable CA, Donowitz GR. Infections in bone marrow transplant recipients. Clin Infect Dis 1994;18:273-84.

2. Zaia JA, Forman SJ. Cytomegalovirus infection in the bone marrow transplant recipient. Infect Dis Clin North Am 1995;9:879-900.

3. Reed EC, Bowden RA, Dandliker PS, Lilleby KE, Meyers JD. Treatment of cytomegalovirus pneumonia with ganciclovir and intravenous cytomegalovirus immunoglobulin in patients with bone marrow transplants. Ann Intern Med 1988;109:783-8.

4. Emanuel D, Cunningham I, Jules-Elysee K, et al. Cytomegalovirus pneumonia after bone marrow transplant successfully treated with the combination of ganciclovir and high-dose intravenous immune globulin. Ann Intern Med 1988;109:777-82.

5. Wingard JR, Chen DYH, Burns WH, et al. Cytomegalovirus infection after autologous bone marrow transplantation with comparison to infection after allogeneic bone marrow transplantation. Blood 1988;71:1432-7.

6. Boeckh M, Stevens-Ayers T, Bowden RA. Cytomegalovirus pp65 antigenemia after autologous marrow and peripheral blood stem cell transplantation. J Infect Dis 1996;174:907-12.

7. Prentice HG, Kho P. Clinical strategies for the management of cytomegalovirus infection and disease in allogeneic bone marrow transplantation. Bone Marrow Transplant 1997;19:135-42.

8. Boeckh M, Myerson D, Bowden RA. Early detection and treatment of cytomegalovirus infections in marrow transplant patients: methodological aspects and implications for therapeutic interventions. Bone Marrow Transplant 1994;14(Suppl 4):S66-70.

9. Boeckh M, Gooley TA, Myerson D, Cunningham T, Schoch G, Bowden RA. Cytomegalovirus pp65 antigenemia-guided early treatment with ganciclovir versus ganciclovir at engraftment after allogeneic marrow transplantation: a randomized double-blind study. Blood 1996;88:4063-71.

10. Einsele H, Ehninger G, Hebart $\mathrm{H}$, et al. Polymerase chain reaction monitoring reduces the incidence of cytomegalovirus disease and the duration and side effects of antiviral therapy after bone marrow transplantation. Blood 1995;86:2815-20.

11. Meyers JD, Flournoy N, Thomas ED. Risk factors for cytomegalovirus infection after human marrow transplantation. J Infect Dis 1986;153:478-88.

12. Bowden RA, Slichter SJ, Sayers MH, Mori M, Cays MJ, Meyers JD. Use of leukocyte-depleted platelets and cytomegalovirusseronegative red blood cells for prevention of primary cytomegalovirus infection after marrow transplant. Blood 1991;78:246-50.

13. Bowden RA, Sayers M, Flournoy N, et al. Cytomegalovirus immune globulin and seronegative blood products to prevent

\section{CONCLUSIONS}

This survey shows that CMV prevention and treatment practices vary widely across different centres in Canada. This is especially true for allogeneic BMT and PBSC transplants in whom CMV infection and disease remains an important problem. A published survey of European centres also demonstrated major differences in the approach to $\mathrm{CMV}$, although details regarding dose and duration of prophylactic, pre-emptive or therapeutic medications were not provided (23). Future improvements in the management of CMV-related problems in this patient group requires well designed, randomized controlled clinical trials that focus on a comparison of different prevention strategies with an analysis of both clinical efficacy and cost effectiveness, a comparison of different therapeutic regimens for active CMV disease and trials assessing new antiviral agents. Improved diagnostic test methodology and standardized definitions would also be important steps towards developing guidelines.

primary cytomegalovirus infection after marrow transplantation. N Engl J Med 1986;314:1006-10.

14. Reusser P, Fisher LD, Buckner CD, Thomas ED, Meyers JD. Cytomegalovirus infection after autologous bone marrow transplantation: Occurrence of cytomegalovirus disease and effect on engraftment. Blood 1990;75:1888-94.

15. Sayers M, Anderson KC, Goodnough LT, et al. Reducing the risk for transfusion-transmitted cytomegalovirus infection. Ann Intern Med 1992;116:55-62.

16. Van Prooijen HC, Visser JJ, Van Oostendorp WR, De Gast GC, Verdonck LF. Prevention of primary transfusion associated cytomegalovirus infection in bone marrow transplant recipients by the removal of white cells from blood components with high-affinity filters. Br J Hematol 1994;87:144-7.

17. Goodrich JM, Bowden RA, Fisher L, Keller C, Schoch G, Meyers JD. Ganciclovir prophylaxis to prevent cytomegalovirus disease after allogeneic marrow transplant. Ann Intern Med 1993;118:173-8.

18. Winston DJ, Ho WG, Bartoni RN, et al. Ganciclovir prophylaxis of cytomegalovirus infection and disease in allogeneic bone marrow transplant recipients. Results of a placebo-controlled, double-blind trial. Ann Intern Med 1993;118:179-84.

19. Schmidt GM, Horak DA, Niland JC, Duncan SR, Forman SJ, Zaia JA. A randomized controlled trial of prophylactic ganciclovir for cytomegalovirus pulmonary infection in recipients of allogeneic bone marrow transplants; The City of Hope-Stanford-Syntex CMV Study Group. N Engl J Med 1991;324:1005-11.

20. Goodrich JM, Mori M, Gleaves CA, et al. Early treatment with ganciclovir to prevent cytomegalovirus disease after allogeneic bone marrow transplantation. New Engl J Med 1991;325:1601-7.

21. Ljungman $\mathrm{P}$, Cordonnier $\mathrm{C}$, Einsele $\mathrm{H}$, et al. Use of intravenous globulin in addition to antiviral therapy in the treatment of CMV gastrointestinal disease in allogeneic bone marrow transplant patients: a report from the European Group for Blood and Marrow Transplantation (EBMT). Infectious Diseases Working Party of the EBMT. Bone Marrow Transplant 1998;21:473-6.

22. Hebart H, Schröder A, Löffler J, et al. Cytomegalovirus monitoring by polymerase chain reaction of whole blood samples from patients undergoing autologous bone marrow or peripheral blood progenitor cell transplantation. J Infect Dis 1997;175:1490-3.

23. Ljungman P, De Bock R, Cordonnier C, et al. Practices for cytomegalovirus diagnosis, prophylaxis and treatment in allogeneic bone marrow transplant recipients: a report from the Working Party for Infectious Diseases of the EBMT. Bone Marrow Transplant 1993;12:399-403. 


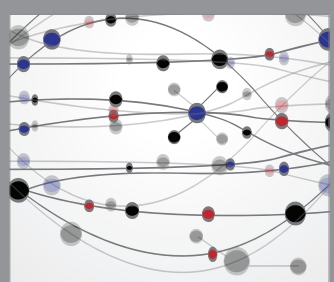

The Scientific World Journal
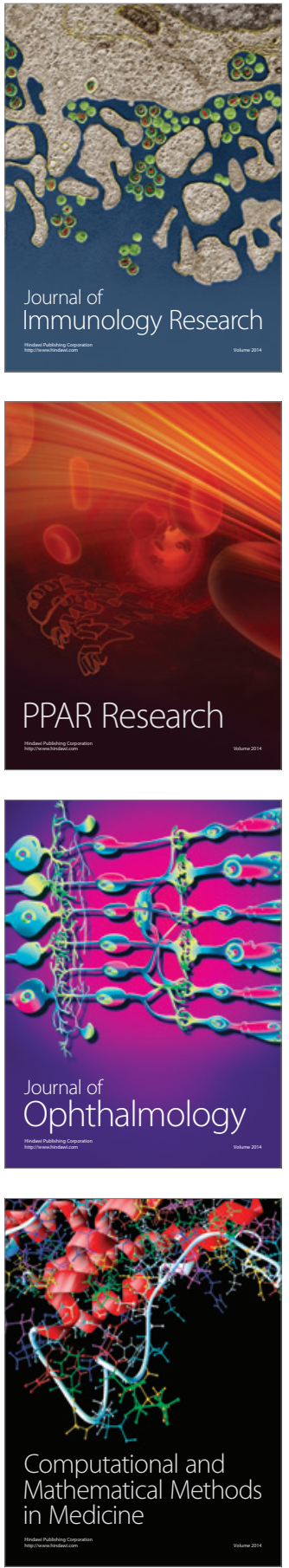

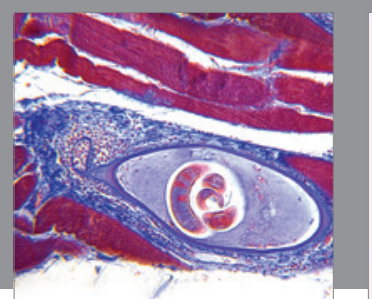

Gastroenterology Research and Practice

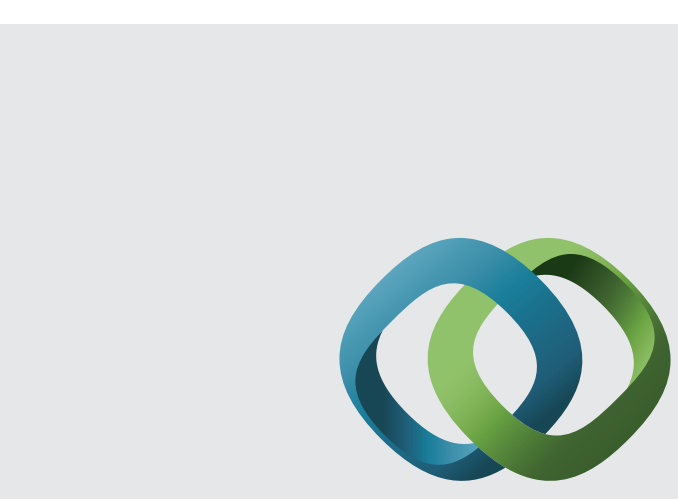

\section{Hindawi}

Submit your manuscripts at

http://www.hindawi.com
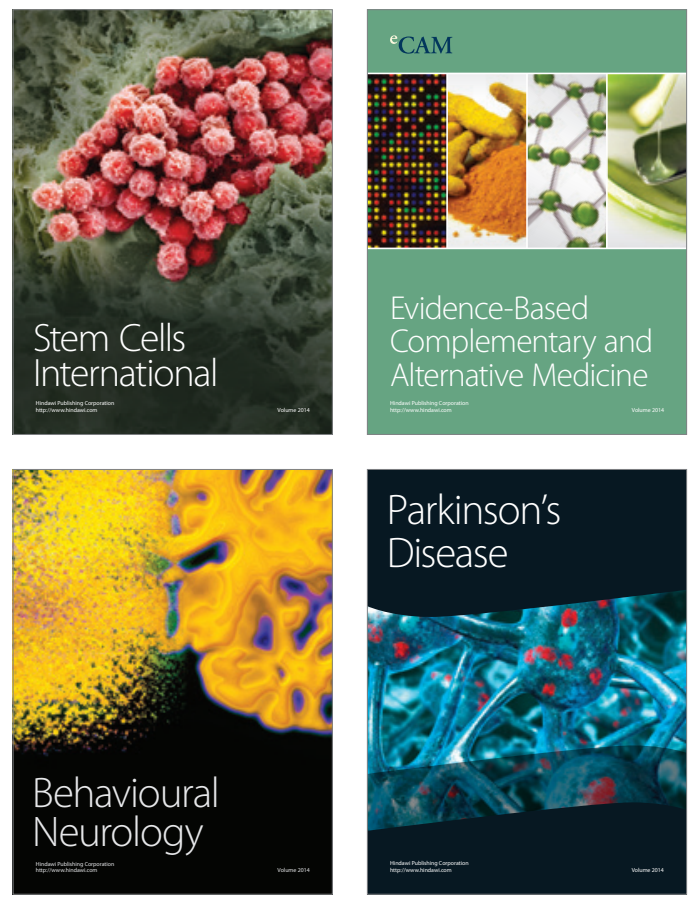
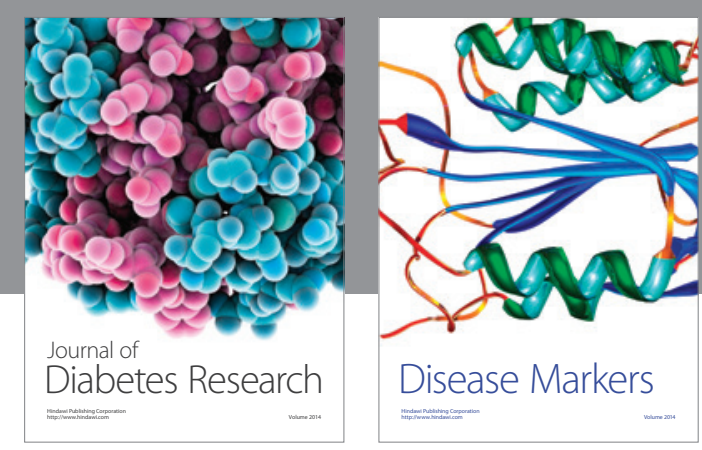

Disease Markers
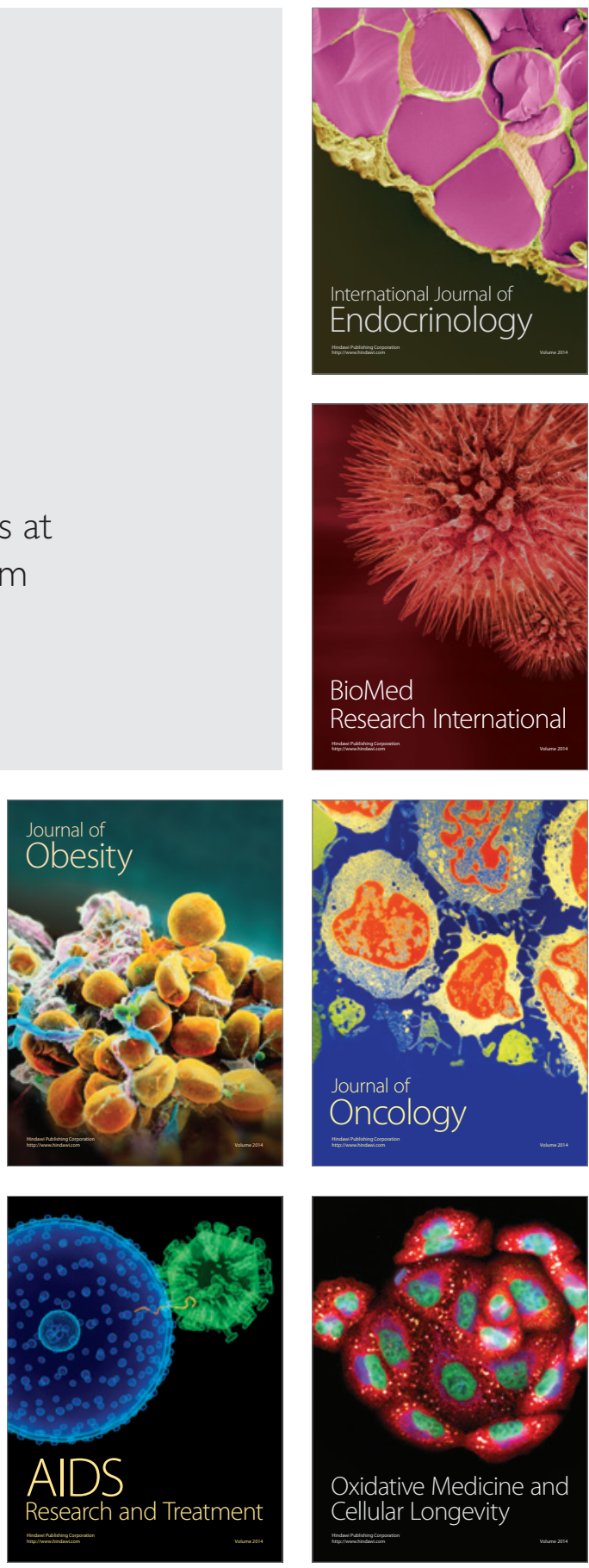